\title{
The Many Facets of ASD in Children, Youth, and Young Adults
}

As Marek [1] advocates, a true editorial identifies and discusses a thesis topic besides introducing the issue articles. Since this special issue is dedicated to our fellow human beings on the autism spectrum, we pursue the view of autism through the neurodiversity lens.

A significant paradigm shift in the approach to autism occurred when talented individuals with autism insisted they represent neurodiversity rather than neuroatypicality. The neurodiversity movement (NM), as Fenton and Krahn [2] explain, includes all autism phenotypes, and others with neurodevelopmental challenges. The NM advocates for better societal support, and acknowledgment that their neurological, cognitive, and behavioral differences represent neurodiversity rather than a pathology requiring a cure. They ask us to "alter [our] view of $\mathrm{Au}$ tism as a pathology, acknowledge diversity of cognitive, adaptive and functional skills amongst all humans, provide the support and resources to those who need it so they can realize their full potential, and include the individual in having a voice in their treatment." In essence, the authors advocate for accepting autism neurodiversity as the "new normal." In her medical ethics journal editorial, Miller [3] notes that autism presents a unique paradox spotlighted by the NM in insisting it is not a disease, and so diametrically opposing pediatricians' experience of the devastating power autism can have. These opposing notions reveal ethical dilemmas: questions of autonomy, decision-making, and intrinsic worth. She elaborates, "It forces us to question the assumption that people with autism can't speak for themselves and to carefully balance the need for treatment with the respect for the person." Mitchell [4], a father to a child with autism, and one of the translators of Higashida's book he wrote as an autistic 13-year-old, notes in his poetic opening that there exists an immense chasm between what we think they are and what they are actually experiencing in their chaotic daily lives. Their unique challenges translate into a considerable diversity of phenotypes, each exhibits a variation of autism but also possible creative and intellectual capacities. Mitchell reiterates that our job is not "to cure" them but rather, "support and help them become longterm contributors to society."

Nicolaidis [5], a primary care physician, with an autistic child, narrates her firsthand experience of the pitfalls inherent in pathologizing ASD individuals, and the change in her view and approach due to the NM. She advocates seeing them "as possessing a complex combination of cognitive strengths and challenges" which can be addressed rather than classifying individuals as showing high or low function autism. She adopted the term "autistic" to show the person and the autism are not separate. The NM, she confirms, recognizes autism as a disability, but sees it as a natural variation rather than a pathology that needs to be "cured." Mottron [6], a psychiatrist and prolific researcher in autism, agrees that "Autism is a natural variant within the human species, rather than an error of nature that should be corrected." His autistic research partner laments that autistic individuals face difficulties obtaining jobs because of damaging perceptions resulting from their frequent portrayal in negative terms. Mottron adds, "Autism's many advantages are not part of the diagnostic criteria" and most educational programs 
focus on eliminating autistic behaviors, and none consider the unique ways autistics learn. Furthermore, autism researchers too are negatively biased when they report brain differences as deficits rather than simply variations of brain organization.

The ASD committee of the International Association of Communication Sciences and Disorders (IALP) acknowledges and views individuals with autism as possessing strengths and challenges, and its major goal is to help improve the lives of children, adolescents, and young adults with autism by various means including expansion of the knowledge of autism via research and dissemination of information. This special issue of Folia Phoniatrica et Logopaedica hopes to fulfill this aim with contributions that address diverse facets of autism.

In this issue, Lilly Cheng, IALP immediate past president, acknowledges the loss of Sara Eyal, our dear colleague and friend. In her introduction to this special issue, Cheng highlights autistic individuals with unique challenges and talents. Scholars from South Africa, Cyprus, Greece, Israel, Canada, and USA contributed articles that touch on important issues, and present interesting findings on aspects of autism.

Adams and colleagues' article [7], “Mothers' Experiences of Feeding Children with Autism Spectrum Disorders in South Africa," explores the daily challenges experienced by South African mothers from varying contexts and cultural backgrounds when feeding their affected children. The authors identify obstacles to successful feeding and their serious consequences as these children's idiosyncratic food selectivity imposes a financial burden that is beyond the economic capacities of these families.

Evidence-based treatment options are sparse for youngsters with autism comorbid with atypical speech profiles and speech intelligibility issues. Petinou's article [8], "Promoting Speech Intelligibility in ASD through the Implementation of Phonologically Similar Stimuli," highlights the successful theoretically driven approach in treating speech sound disorders in a child with autism from a Greek-Cypriot linguistic milieu. This is an important contribution to treatment options for children with autism and atypical speech profiles.

Christopoulou and colleagues' article [9], "Colourful Semantics in Cypriot-Greek-Speaking Children with Autism Spectrum Disorder," reports on the successful use of the Colourful Semantics approach in an intervention program for morphosyntactic and semantic lags of CypriotGreek-speaking children with autism. The study provides a welcome increase to the sparse treatment choices for Cypriot-Greek-speaking children with autism.
The Vogindroukas and colleagues' article [10], "Developmental Profile of Social Communication: Findings from Typically Developing 2-8 Year-Old Greek Children," reports on an adaptation of the English Developmental Profile of Social Communication Parent Questionnaire for typically developing Greek speaking children. Local benchmarks facilitate better understanding of social communication challenges in children with autism and other developmental disorders. The resulting profile provides an ecologically valid platform for effective treatment planning.

A marked hindrance to targeted treatment in autism is its heterogeneity and diversity of autism features over time. The Hus and Segal article [11], "Functional Communication Profiles of Children and Youth with Autism: A Roadmap to Therapeutic and Educational Interventions," addresses this obstacle with construction of communication profiles of children and youth with autism. The authors encourage employing functional profiles routinely to guide targeted individual educational and therapeutic plans.

Phonological processing efficiency underlies language and literacy skill acquisition. Jokel and colleagues' study [12], "Associations and Dissociations among Phonological Processing Skills, Language Skills, and Nonverbal Cognition in Individuals with Autism Spectrum Disorder," aimed to uncover the salient variables in this fundamental function in individuals with autism and intact cognitive abilities. The study showed reduced phonological memory, and more robust phonological awareness efficiency - an important finding for clinicians and researchers.

Westby's article [13], “The Effects of Digital Exposure Time on Children with Autism," focuses on children's increasing time on screens and engagement with digital media, and the impact it may have on children with autism. Westby describes why they are at higher risk of negative consequences, and offers a 3-component framework in which the child, context, and content are considered for selecting appropriate digital media to benefit these children.

Johnson's article [14], "US Pilot Curriculum for Transitioning Students with Autism Spectrum Disorders from High School to College and the Workforce," examines a locally constructed pilot curriculum to address transitioning needs of high school students with autism to vocations or college admission. Here, Johnson astutely identifies important curriculum enhancements to improve long-term success in gaining skills requisite for employment and independent living. 
Ferman's article [15], "Morpho-Lexical Processes in Children with ASD: Evidence from Artificial Word Learning," showed children with autism and intact cognitive and language function demonstrated that they are capable of learning Hebrew artificial words. They successfully applied their morpho-lexical pattern knowledge in this learning paradigm; however, their seemingly typical lexical learning mechanism lagged in efficiency, concluded Ferman.

The articles in this special issue of Folia Phoniatrica et Logopaedica address some of the many complex facets of autism. The purpose here is to enrich the bank of knowl- edge on autism, and so assist our colleague clinicians, researchers, and autism advocates in their efforts to support and improve the lives of individuals on the autism spectrum.

Yvette Hus

Kakia Petinou

Osnat Segal

\section{Conflict of Interest Statement}

The authors have no financial or nonfinancial conflicts of interest to declare, and there were no funding sources in the publication of this editorial.

\section{References}

1 Marek MW. Answer to Question: How to write an editorial. May, 2, 2016. https://www. researchgate.net/post/How_to_write_an_editorial_for_a_journal.

2 Fenton A, Krahn T. Autism, neurodiversity and equality beyond the 'Normal'. Journal of Ethics in Mental Health JEMH. 2007 Nov; 2(2):1-6.

3 Miller KK. The Autism Paradox. AMA J Ethics. 2015 Apr;17(4):297-8.

4 Higashida N (Yoshida KA, Mitchell D, translators). The Reason I Jump: The Inner Voice of a Thirteen-Year-Old Boy with Autism. Audiobook. New York: Random House; 2013. https:// www.youtube.com/watch?v=UE9PAT2dG8c.

5 Nicolaidis C. What Can Physicians Learn from the Neurodiversity Movement? Virtual Mentor (Now AMA J. Ethics) 2012 June;14(6):503-510. DOI: https://doi.org/10.1001/virtualmentor.20 12.14.6.oped1-1206.
6 Mottron L. Changing perceptions: the power of autism. Nature. 2011 Nov;479(7371):33-5.

7 Adams S, Dadabhay A, Neille J. Mothers' experiences of feeding children with Autism Spectrum Disorders in South Africa. Folia Phoniatr Logop. https://doi.org/10.1159/000507928.

8 Petinou K. Promoting speech intelligibility in ASD through the implementation of phonologically similar stimuli. Folia Phoniatr Logop. https://doi.org/10.1159/000511346.

9 Christopoulou M, Voniati L, Drosos K, Armostis S. Colourful semantics in CypriotGreek-speaking children with Autism Spectrum Disorder. Folia Phoniatr Logop. https:// doi.org/10.1159/000512157.

10 Vogindroukas I, Chelas EN, Petridis N. Developmental profile of social communication: findings from typically developing 2-8 year old Greek children. Folia Phoniatr Logop. https://doi.org/10.1159/000511901.
11 Hus Y, Segal O. Functional communication profiles of children and youth with Autism: a roadmap to therapeutic and educational interventions. Folia Phoniatr Logop. https:// doi.org/10.1159/000510056.

12 Jokel A, Armstrong E, Gabis L, Segal O. Associations and dissociations among phonological processing skills, language skills and non-verbal cognition in Individuals with Autism Spectrum Disorder. Folia Phoniatr Logop. https://doi.org/10.1159/000505744.

13 Westby C. The effects of digital exposure time on children with Autism. Folia Phoniatr Logop. https://doi.org/10.1159/000506682.

14 Johnson K. US pilot curriculum for transitioning students with Autism Spectrum Disorders from high school to college and the workforce. Folia Phoniatr Logop. https://doi. org/10.1159/000509836.

15 Ferman S. Morpho-lexical processes in children with ASD: evidence from artificial word learning. Folia Phoniatr Logop. https://doi. org/10.1159/000512849.
The Many Facets of ASD in Children, Youth, and Young Adults
Folia Phoniatr Logop 2021;73:161-163 DOI: $10.1159 / 000516048$ 